\title{
EDITORIAL
}

\section{LA INVESTIGACIÓN EDUCATIVA BASADA EN LAS ARTES YA NO NECESITA MÁRTIRES}

\section{UN PEQUEÑo HOMENAJE A LA PRÁCTICA DOCENTE DE MARK ROTHKO}

ARTS-BASED EDUCATIONAL RESEARCH NO LONGER NEEDS MARTYRS: A SMALL TRIBUTE TO MARK

ROTHKO'S TEACHING PRACTICE

\section{Dr. José María Mesías-Lema}

Universidad de A Coruña (D) https://orcid.org/0000-0001-8278-7115

Hace diez años, cuando esta escuela comenzó a funcionar, se consideraba que los métodos de arte progresistas eran innovaciones y experimentos poco dignos de fiar. Actualmente, nuestro método ya no necesita mártires. Se ha extendido a varias escuelas públicas que se han distinguido en su aplicación y que están siendo muy solicitadas por este motivo. (Rothko, "Cuaderno de apuntes", 1934, p. 44)

Los manuales de historia del arte están repletos de textos críticos sobre la maravillosa obra de Rothko. Lo asombroso es descubrir que, uno de los artistas más transcendentes del siglo XX, poseía una pasión cumplida durante más de veinte años: enseñar arte a niños. Casi nadie, entre los que me incluyo, éramos conocedores en profundidad de que Marcus Rothkowitz se había ganado la vida como profesor del Brooklyn Jewish Center de Nueva York. Y no un profesor cualquiera, sino uno de los buenos. En cuyo caso, este "ganarse la vida" no equivale a "ganarse un sueldo" como sustento para poder pintar. Tal vez, podemos legitimar esta afirmación porque, a través de la lectura de sus escritos personales, abruma el rigor, la ética, la entrega y la responsabilidad en estas dos facetas, jamás descuidadas. Pintura y enseñanza, confluyen durante un período de veinte años y a lo largo de toda su vida. Siempre he admirado la coherencia de estas personas.

Su primer artículo publicado en 1934, "New Training for Future Artists and Art Lovers", marca el inicio del pensamiento del artista basado en su observación y experiencia en dentro del aula. Centra su discurso en tres ejes: 1) el arte y el lenguaje visual y plástico para todos los niños, no sólo para aquellos que poseen talento 2) valoración de las producciones artísticas creadas por los niños 3) el valor del arte para la creación como parte fundamental de la vida en la infancia y adulta. Rothko desarrollará estas ideas en varios escritos que ahondan en la necesidad de que la infancia narre, se exprese y argumente ideas a través del lenguaje artístico. Y para ello, podríamos resumir su discurso, acerca de la enseñanza-aprendizaje del arte, en cuatro conceptos:

- Arte como lenguaje: es un método de registrar nuestra experiencia vivida e imaginada, nuestras reacciones personales, con la misma sencillez que hacemos otras tareas cotidianas, pero a través del lenguaje plástico y visual. Los niños tienen siempre ideas buenas y las expresan de tal modo que sentimos su paisaje interior: "Si no lo crees, observa cómo trabajan estos niños y verás cómo organizan las formas, las figuras y los paisajes según criterios pictóricos, utilizando, cuando les es necesario, muchas de las reglas de la perspectiva óptica y de la geometría, aunque sin ser conscientes de estarlo haciendo. Hacen lo mismo que cuando hablan y utilizan inconscientemente las reglas gramaticales" (p. 10).

- El aula como forma de vida: la clase de arte crea comunidad y alteridad, respeto hacia los otros y hacia sus producciones artísticas, porque la experiencia estética colectiva les ayuda a revivir el placer artístico en las obras de los demás. Cuando entran en el aula todos los materiales están dispuestos para ser empleados y experimentados. Todos los estudiantes vienen llenos de ideas y, a medida que aumenta su experiencia, ganan seguridad en la vivencia de los procesos artísticos. Cada niño trabaja con su propia idea con un nivel de exigencia muy alto, porque formarán parte de una exposición colectiva: "De acuerdo, que los críticos vean la obra de nuestros niños. Todo está aquí: fábricas, muelles, calles, muchedumbres, montañas, lagos, granjas, animales, hombres, mujeres, barcos, agua. Aquí está el arte social” (p. 11).

- La importancia de los procesos creativos en la infancia: Todos los niños admiran los procedimientos y técnicas plásticas, por tanto, la enseñanza tiene que aumentar su sensibilidad en base a la experimentación, porque no es nuestra labor crear artistas. El acto creativo es una acción social. Imagínense a los estudiantes en una isla desierta, la inactividad y el aburrimiento, son necesarios para despertar el instinto y dejarles crear a sus anchas. Teniendo en cuenta que el periodo creativo se agota, normalmente, antes de los 12 años, y que este es de muy corta duración, los procesos artísticos en la infancia son de vital importancia para la vida adulta. Pero dejarles libertad no es sinónimo de que el alumno haga lo que desee, por ejemplo, Rothko desarrolla una lista interminable de elementos del lenguaje visual para trabajar en la infancia. 
- El rol profesor-artista: Mark Rothko definió su faceta, de este modo, en un texto de 1941. Conceptualizó esta doble tarea, en donde la función docente reside en estimular y sugerir soluciones concretas para superar los bloqueos en el proceso artístico, sin imponer normas que estanque su imaginación. "El profesor perfecto que haya de enseñar una actividad artística creativa debe poseer un doble perfil. Primero, al igual que cualquier otro profesor, debe tener la perspicacia y la preparación suficientes para evaluar la personalidad, la formación y las potencialidades del niño; su mera presencia y su comportamiento deben crear una atmósfera de relajación y confianza; y debe compartir la perspectiva social de aproximarse al proceso educativo del que forma parte esta actividad. Por otro lado, y este es realmente el requisito importante de este estudio, el profesor debe poseer la sensibilidad de un artista. El arte debe ser para él un lenguaje claro y directo capaz de inspirar en el alumno el entendimiento y la exaltación que éste intrínsecamente conlleva. El profesor-artista suele ser quien mejor lleva esta misión a su fin" (en López-Remiro, p. 54).

¡Ojalá hubiéramos sido sus alumnos! Esa es la sensación que permanece, como trementina suspendida en el aire, después de haber leído sus escritos personales. Podemos imaginar sus clases, el espacio de creación individual que ofrecía a sus estudiantes, desde la confianza al error, al fracaso, a lo procesual, a lo expositivo como manera de engrandecer las producciones de la infancia... En definitiva, no podemos decir que hiciese una Investigación Educativa basada en las Artes porque simplemente ni existía esa expresión, ni la necesidad de etiquetar todo cuanto sucedía en los procesos educativos. De hecho, criticaba abiertamente las modas educativas de los "falsos teóricos, decoradores de interior de la historia social y de la filosofía, que no tienen ninguna relación con la verdad, y que distorsionan los hechos para comercializar sus frágiles maquinaciones" (p. 35). No obstante, su saber docente, no como una práctica aislada, sino profunda en tiempo y formas, en su saber pragmático e intelectual, da coherencia al hecho de ser profesor-artista y al hecho de investigar artísticamente sobre la práctica docente.

Si sus primeros textos se centraban en el rol docente y en los procesos de enseñanza-aprendizaje de las artes en la infancia, cuando su carrera artística empezó a calar a nivel internacional, siguió ejerciendo como profesor universitario en la Escuela de Bellas Artes de California, en la Universidad de Colorado y en la Universidad de Tulane. Su último texto, con la aceptación del doctorado Honoris Causa en Bellas Artes por la Universidad de Yale en 1969, sería todo un vaticinio de los derroteros del arte contemporáneo:

"Cuando era joven el arte era una práctica solitaria: no había galerías ni coleccionistas no críticos ni dinero. Sin embargo, era una edad de oro, pues no teníamos nada que perder y sí toda una visión que ganar. Hoy ya no es lo mismo. Es una época de inmensa abundancia de actividad y de consumo. No me atrevo a aventurar cuál de las dos circunstancias sea mejor para el arte. Sin embargo, si sé que muchos de los que se ven impelidos a este modo de vida buscan desesperadamente bolsas de silencio en que arraigar y crecer. Todos esperamos que las encuentren" (en López-Remiro, p. 219). 

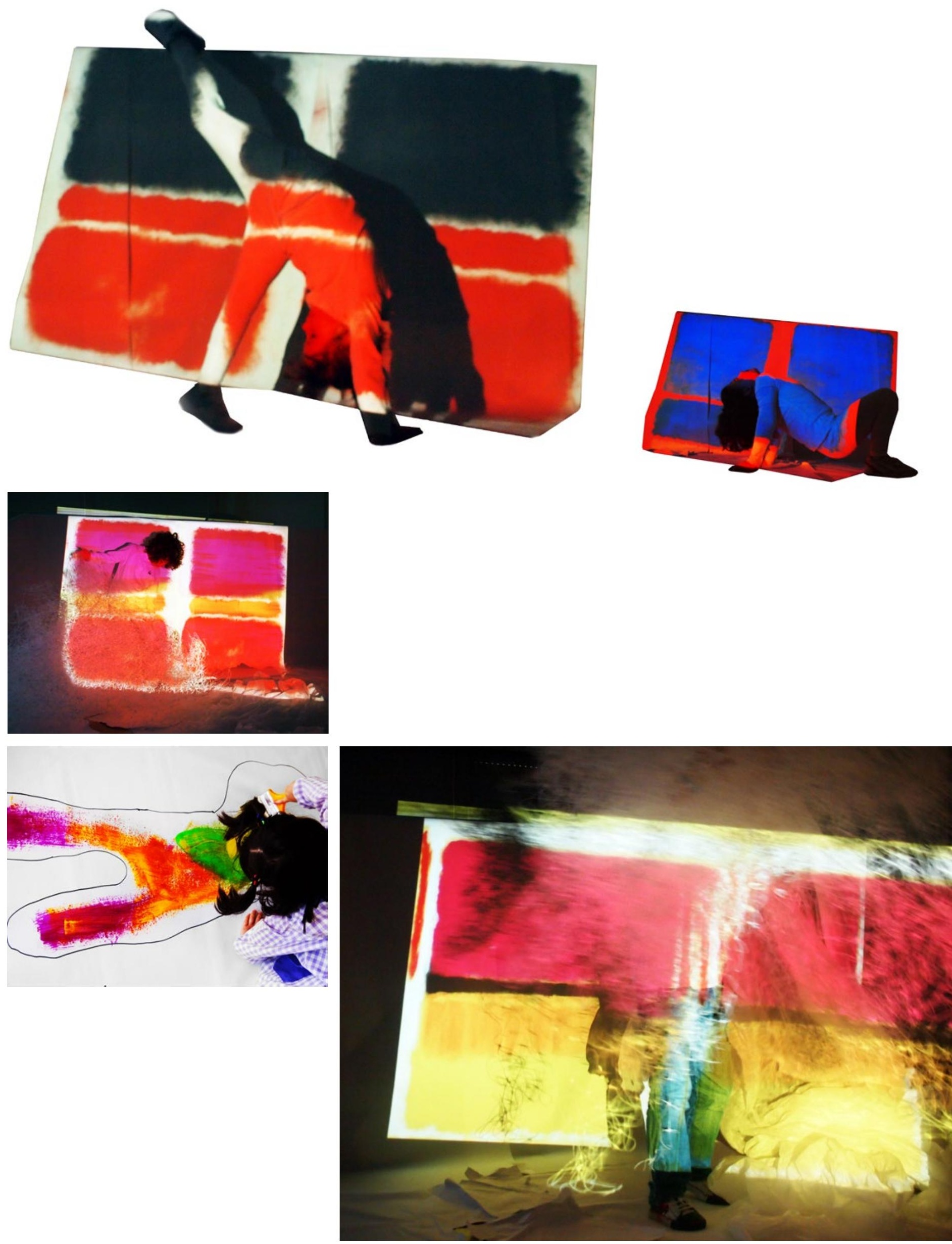

Imágenes 4, 5, 6, 7, 8 y 9. "Proyecto con alumnado de Infantil en el CEIP de Sigüeiro, 2016", Mesías-Lema, 2019, p. 172-173. 
Todo su discurso, considerado desde una retrospectiva de casi 90 años, sigue hoy plenamente vigente para ser asumido por docentes y profesionales de la educación artística. De hecho, en 2016, desde un aula de infantil, quisimos rendir un pequeño homenaje a Rothko como profesor-artista, por su valiosísima aportación para la enseñanza artística en la infancia. Partiendo de sus ideas, de sus obras como grandes atmósferas de color, como una epidermis cromática que invade al espectador, decidimos mimetizarnos con ellas, con movimientos sintiendo las manchas del artista y expresando con el cuerpo la energía y vitalidad de las obras (Mesías-Lema, 2019). Pretendíamos que el alumnado experimentase la obra de Rothko desde dentro, tal y como él relató en alguna entrevista: pinto lienzos de gran formato porque estoy dentro de ellos. "Yo concibo mis cuadros como obras dramáticas; las formas en los cuadros son los actores. Son creadas por la necesidad de contar con actores capaces de conmover y ejecutar gestos sin vergüenza alguna. Ni la acción ni los actores son previsibles, ni pueden describirse a priori. Dan comienzo a una aventura desconocida en un espacio igualmente ignoto" (pp. 100-101).

La Investigación Educativa basada en las Artes bebe de referentes clásicos como Dewey, Pierce, Schön y nace desde la "epistemología pragmatista: rescatar y trabajar con la experiencia profesional vivida, como punto lanzadera para la construcción de nuevo conocimiento a través del análisis, reflexión y crítica de la misma" (Mesías-Lema, 2012, p. 233). En el ámbito de la educación artística fue María Jesús Agra (1994), referente internacional en este campo, quien inició esta línea y sentó las bases teóricas hace más de treinta años. Defendió un rol docente desde la praxis del aprendizaje artístico basado en planes de acción. Este avance contribuyó notablemente a entender la práctica e investigación en educación artística como un espacio de integración de la acción artística como modelo de investigación educativa. Podemos considerar esta tesis como la pionera de la Investigación Educativa basada en las Artes en nuestro país. Posteriormente, Agra (2005) desarrollaría el corpus metodológico desde la narrativa, y ampliado desde una perspectiva epistemológica y argumentativa por Ricardo Marín (2005). La mentoría de científicos senior como Agra y Marín-Viadel, infundió a toda una generación de investigadores, la confianza suficiente para abrir campos emergentes en terrenos movedizos, siempre desde la inquietud intelectual de querer cambiar la enseñanza del arte en las aulas.

Esta revista quiere ser un altavoz de la calidad de las prácticas docentes y de aprendizaje en torno a las artes, pero desde la investigación. Las prácticas docentes desprovistas de una argumentación artística y pedagógica sólida y profunda, desvinculada de los procesos investigadores rigurosos y estables en el tiempo, no construyen conocimiento ni ayudan a avanzar en el campo científico. Estamos de acuerdo con Garcés (2021) cuando afirma que en educación se ha reducido el debate a la rivalidad y el conflicto entre recetas superficiales, con la innovación como telón de fondo del discurso neoliberal. Por ello, queremos crear un espacio científico para la comunidad de profesionales que transitan, al mismo tiempo y de manera indisociable, entre el arte y la educación, como dos mundos próximos, interconectados y fusionados. Es nuestra tarea, como área científica, responder con nuestras acciones, demandas y necesidades a una investigación viva, orgánica y transferible. Debemos observar como la Investigación Educativa basada en las Artes, es regeneradora también de un cambio en la práctica de la educación artística, aquella que está constantemente en fricción acerca de las realidades sobre las que habla. Solo así podemos reconstruir el campo epistemológico de la educación artística en contextos culturales, sociales y educativos.

Hemos gastado demasiada energía tratando de explicar a profesionales, ajenos a nuestro campo, lo que era o lo que dejaba de ser una investigación en educación artística. La Investigación Educativa basada en las Artes ya no necesita mártires. Necesita ser visibilizada, utilizada por los propios expertos del área y defendida por investigadores que arriesguen por esta línea, desde la calidad y la argumentación científica. La creación de esta revista es un intento colectivo para apreciar nuestro campo de investigación, divulgarlo y sentirnos orgullosos de él. Pretendemos que este espacio científico sea un lugar 
de diálogo, de debate y de riesgo. Todos los inicios son difíciles pero emocionantes. Como dijo Rothko: "el arte es, para nosotros, una aventura hacia un mundo desconocido, que sólo puede ser explorado por aquellos que estén dispuestos a asumir riesgos" (1943, en López-Remiro, p. 69)

¿Si no lo hacemos nosotros, quién lo va a hacer?

\section{REFERENCIAS BIBLIOGRÁFICAS}

Agra Pardiñas, M. J. (1994). Planes de acción: una alternativa para la Educación Artística. Editorial Universidad Complutense de Madrid.

Agra Pardiñas, M. J. (2005). "El vuelo de la Mariposa: la investigación artístico-narrativa". En Marín-Viadel, R. (ed). Investigación en Educación Artística. Editorial Universidad de Granada.

Garcés, M. (2021). Escuela de aprendices [School of apprentices]. Galaxia Gutenberg.

López-Remiro, M. (2007). Mark Rothko. Escritos sobre arte (1934-1969). Paidós.

Marín-Viadel, R. (2005). La "investigación educativa basada en las artes visuales" o "arteinvestigación educativa" Investigación en Educación Artística. Editorial Universidad de Granada. En Marín-Viadel, R. (ed). Investigación en Educación Artística. Editorial Universidad de Granada

Mesías Lema, J. M. (2012). Fotografía y educación de las artes visuales: el fotoactivismo educativo como estrategia docente en la formación del profesorado. Editorial Universidad de Granada.

Mesías Lema, J. M. (2019). Educación artística sensible: cartografía contemporánea para arteducadores. Graó.

Moreno Montoro, Mª. I. y López-Pelaez, Mª. P. (coords.) (2016). Reflexiones sobre investigación artística e investigación educativa basada en las artes. Síntesis.

Rothko, M. (1934). "New Training for Future Artists and Art Lovers". The Brooklyn Jewish Center Review, pp. 10-11. 